\title{
Arbor
}

\section{Recuerdo, crónica, pasión y catarsis}

\section{Pilar de Aristegui}

Arbor CLXVIII, 663 (Marzo 2001), 293-308 pp.

La pintura de Pilar de Aristegui explicada cronológicamente, y en sus diversas etapas. "Estas etapas están marcadas o inspiradas por los cambios de vida, que he disfrutado o padecido, y por la lógica evolución que muchos artistas experimentamos. Creo que la mejor manera de describir el origen y la evolución de mi pintura es dividirla en cuatro etapas, que aunque están claramente separadas, asumen al mismo tiempo, diversos grados de intensidad, y están unidas todas ellas por el mismo hilo conductor».

\section{La Pasión}

La pasión por la pintura. La pasión por ser pintora. La pasión por conocer la pintura de otros países y disfrutar de otras formas, distintas, de expresión. Comprender cómo y porqué, otros pueblos se expresan plasticamente o vitalmente, de una manera diversa.

\section{«Pilar de Aristegui: Recuerdo, crónica, pasión y catarsis»}

Por los años 80 Carmen Martín Gaite, después de dar unas conferencias en Nueva York, cenaba en nuestra casa de Washington, donde, en ese momento, Carlos mi marido, dirigía la Oficina Cultural de España. Llegó Carmen muy elegante, con un delicioso sombrero, y recuerdo que dijo venir de Nueva York, por cuya Quinta Avenida, se había paseado con dicho sombrero, y que entonces, había sentido que eso era el triunfo. 
Pensé entonces que yo tenía ese mismo año 1984, unos meses más tarde, mi primera exposición en Nueva York: «Spain is a Festival», pero no sabía que sucedería; mi situación era de curiosidad y anhelo. De todas maneras, era mi primera exposición en Nueva York, y Nueva York en ese momento, era la capital del Arte. No sabía como funcionaban las cosas en ese país, pero ya aprendería,

Pero no adelantemos acontecimientos. Voy a empezar por la primera parte:

\section{El origen: El recuerdo}

Mi infancia fue una infancia feliz, en San Sebastián, en una familia con aficiones artísticas. Mi madre pintaba, hacía unas acuarelas de matices exquisitos; mi tia Magda pintaba también, y mis tíos René y Juan tocaban el cello y el violín y mi madre les acompañaba al piano.

Pero el fogonazo de luz que me mostró un mundo mágico de color, luz e imaginación se produjo en mi primera visita al Museo del Prado, cuando tenía 8-10 años. No se si había visto otro autor, pero recuerdo sólo «El jardín del Paraíso» de El Bosco. Yo quería entrar en ese universo y quedarme en él, para poder llegar a conocer cada detalle de ese mundo extraordinario y visionario.

Mi primer impulso para pintar fue recordar los momentos felices, rodeada de las personas queridas. Eran fiestas familiares, la primera comunión de mis hijos, escenas de vida cotidiana en nuestra casa de Ibiza, aquella casa que habíamos hecho poco a poco, y que ofrecía grandes y frescas sombras, lugar ideal para pintar en el verano.

Luego vendrían los recuerdos de los distintos países donde habíamos estado: los blancos paisajes nevados de Suecia, con un paseo en trineos pintados en vivos colores, tirados por renos, de noche, con la luz de las antorchas cruzando la oscuridad, o las pistas de hielo con los patinadores vestidos de tantos colores.

Más tarde con la explosión de vida y de color que imperan en Brasil, produje una exposición, que intentaba ya contar lo que veía, en el momento, no ya filtrado por el recuerdo, como sucedía en la etapa anterior.

Esta etapa que llamo «de crónica», se consolidó al llegar a España de vuelta de Brasil.

$\mathrm{Al}$ asistir a una serie de fiestas populares, llenas de vida, color y tradición, y sentir la alegría y el vigor de mi país y sus gentes, pensé hacer una exposición que se llamara «España es una Fiesta», ya que así la veía yo. 
Recuerdo, crónica, pasión y catarsis

La documentación me llevó a conocer una serie de datos sobre las fiestas en cuestión: «Moros y cristianos» que se celebra en todo el Mediterráneo, tiene su origen en el siglo IX, por ejemplo, y son muchas las fiestas en las que todo el pueblo, sea en Elche o Javea, participa.

El objetivo principal era, como decía, la crónica, contar como es mi país, de que manera gozan y celebran la vida, sus gentes. Los colores serían fuertes, intensos, con una paleta cromática muy vibrante.

Lo que yo no sabía, cuando los pintaba, es que esos cuadros se expondrían en Nueva York y que con el título «Spain is a Festival» el cartel anunciador estaría en la Quinta Avenida. La Oficina de Turismo de España, que albergaba la exposición era un espacio hermoso y muy activo.

La Secretaría de Turismo eligió esos cuadros para el calendario turístico de España de 1985.

Para entonces nosotros estábamos destinados en Washington, y al volver yo allí, me encontré con una llamada de María Landis extendiéndome, en nombre de su Gobierno, una invitación para viajar a Guatemala.

Siempre que hablo de América la primera palabra que viene a mi mente es: MAGIA.

Guatemala duele de pura belleza. Es su paisaje, son sus gentes, y son unas tradiciones que, heredadas de España, han sido bañados en los misterios mágicos mayas. Dos mundos de formidable personalidad se encuentran: el uno con la influencia todavía poderosa de los libros de caballería, pero despertando a una época de fecunda creación, el otro con la intensa imaginación de la mitología maya y el asombro de lo que se desarrollaría ante sus ojos.

La exposición que surgió de ese viaje, sería un acto de amor, y una relación con América, que aunque ya había sido iniciada, años antes, desde mi infancia, con los relatos escuchados en mi casa, y luego mis propios viajes o estancias en América, se convertiría en una pasión, que me impulsa, recurrentemente, a pintar sobre América, su flora, su fauna, sus gentes, sus personajes.

El camino lo hemos hecho juntos; unas veces con dolor, otras las más, con amor, y siempre con la misma lengua y la misma cultura.

Yo tenía que plasmar eso en formas y colores. No fue difícil. El color en Guatemala es original y de notables contrastes. Quise sobre todo pintar a la mujer guatemalteca. Siendo la columna vertebral del país, ya que en esa época sufrían a la guerrilla y al ejército, y no quedaba otro remedio que criar a los hijos, cultivar los campos y seguir adelante, no dejaban por un momento esa afabilidad en el trato que les distingue, y esos elegantes atuendo, que su tradición textil ha conservado a través de los 
tiempos. Mi primer contacto con las fiestas populares guatemaltecas fue «Los Barriletes» en Santiago Zacatepeque, entre Antigua y Guatemala capital. Cientos de cometas (»barriletes») acariciaban el aire, intentando así, enviar un mensaje a las personas queridas, ya residentes en el Cielo. Los colores de las cometas, unido al color naranja intenso de las flores y los miles de velitas encendidas, eran el espectáculo más alegre y esperanzador que se podía imaginar para la ocasión. (1)

La crónica empezaba ya a fundirse con la pasión.

El director del Museo de Folk Art (Arte Popular) de Nueva

York, Robert Bishop, escribía «Pilar de Aristegui es una artista de su tiempo y para el futuro. Con su vibrante paleta cromática y vitalidad de la ejecución, crea pintura, que gustará tanto a los amantes del arte del mañana, como gusta a nuestra generación...». Y añadía»...Cuando visitaba Guatemala, como huésped del Gobierno, las ideas para los cuadros de esta exposición, surgieron cuando la artista pudo observar a los indígenas tejiendo sus extraordinarias telas. Son cuadros de una artista solida y segura, que, con inusual habilidad transmite una intensa curiosidad hacia las gentes que pinta. Otra característica de su trabajo es un interés profundo por sencillas, y al mismo tiempo, complicadas composiciones» (2).

Había encontrado un tema que me interesaba profundamente: la gente y como la gente celebraba sus momentos de alegría, ahuyentando la derrota y sus tristezas y como lo habían perpetuado a través del Atlántico y a través de los siglos. Y todo ello con las pacíficas armas del movimiento y el color (3). Seguía viviendo en Estados Unidos y, a través de diversos viajes por los Estados de Texas, Florida, Nuevo Méjico y California, tuve la oportunidad de conocer las mismas fiestas de España y Guatemala, a veces solo con algunos nombres distintos. "Los Pastores» en Tejas; «Moros y Cristianos» y «los Matachines» de Nuevo Méjico; «Desembarco de Hernando de Soto» de la Florida, ect.

Así surgió la doble exposición «U.S.A. is a Festival».

Empecé a trabajar al día siguiente de terminar la exposición de Guatemala. Era un proyecto que tendría dos partes:

Una exposición de fiestas populares netamente norteamericanas que se expondría en la Galería Portal's de Chicago y otra de fiestas populares de origen español, que tendría lugar en la Galería Carega de Washington D.C.

El contacto con el mundo indígena norteamericano significó la apertura de unos nuevos y magníficos horizontes en mi pintura: los colores eran diferentes, los movimientos con ondulaciones distintas y con una extraordinaria fuerza en su simbolismo. 
Los franciscanos en Tejas representaban para los indígenas «Los Pastores», especie de Auto Sacramental en los días de Navidad, donde aparece la Virgen, el Niño Jesús, el Arcángel Gabriel, el demonio, los pastores, toda la iconografía tradicional española.(4)

Me entusiasmaba ese mundo y quería profundizar en él; realizar estudios de algunas fiestas que se repetían en tantos lugares diversos y separados por miles de kilómetros; fiestas que se expresaban partiendo de un mismo origen, pero con una infinita variedad en la expresión, tanto en el simbolismo de sus personajes, como en la expresión cromática.

Las exposiciones quedaron fijadas para junio del 1988 pero a mi marido le destinaron a Kenia y todo cambió súbitamente.

Dejé todo organizado lo mejor que pude y partimos hacia Africa, pensando encontrar un país de gran riqueza etnográfica. Pero encontré un país modernizado, donde era difícil encontrar las viejas tradiciones.

La flora y la fauna eran magníficas, y ya que yo quería ser cronista y pintar lo que veía, empecé a interesarme por la flora y fauna extraordinarias que encontré en aquel país. Así surgieron dos exposiciones, las dos llamadas «Kenia, la Bella», que tuvieron lugar en la sede de Naciones Unidas de Nairobi, y la segunda en la Galería Peironcely de Madrid (jque experiencia estupenda exponer en Peironcely!). La naturaleza inmensa, grandiosa y avasalladora me hizo buscar otras texturas, y sobre todo, otra paleta cromática, donde verdes y azules se apoderasen del lienzo, creciendo también los personajes que protagonizaban frecuentemente las mujeres Masais, con sus magníficas «kangas» o capas de tejidos ocres, rojos y blancos.

De esta exposición del año 91, me gustaría recordar un extracto de algunos de los críticos que más me han conmovido, porque me sentí comprendida y en una misma onda emocional. Escribía Carmen Rocamora: "Atrás quedaron sus «Mujeres de Ipanema», poseedoras de esa gracia ingenuista de su primera época tan cercana a la pintura "naif», que se han convertido en un eslabón inconsciente de su clasificada belleza temática. Porque entonces, su acción estaba subordinada al sentimiento, y, su impetu de juventud, volcado en representar las señas de identidad plástica de una corriente popular, de la que era sin duda una de sus máximos exponentes.

Pero Kenia ha sido sobre todo, el descubrimiento del mundo del color, de su carga pasional y de su humano poder de expresión. El dominio del drama de la luz y de la sombra, hace de la pintura de este último período, el más prodigioso símbolo de su euforia individual, y de su madurez interpretativa (5). En otra visión espléndida de la misma exposición decía Manuela Mena: «La nueva exposición de Pilar de Aristegui, en torno a la fauna y flora de Kenia, es resultado de su estancia de varios años en ese país. Revela un estilo plenamente formado y una decidida vocación por un 
tipo de pintura que, aunque tenga sus raíces en lo "Naif», ha evolucionado hacia algo más complejo, en que la naturaleza no se presenta de una forma sencilla, sino con matices que rozan el simbolismo y, en algunos casos, un decidido surrealismo...»espacios silenciosos, llenos de paz y en su silencio, teñidos de una cierta melancolía. Es, quizás, una visión interior, un reflejo en el espíritu de un mundo difícil, de una naturaleza que puede llegar a ser hostil, que sus más bellas flores pone por delante, como si fueran una muralla defensiva, que impida nuestro avance en el espacio misterioso, tal vez amenazador que hay tras ella..». (6)

Nunca me he preocupado mucho de analizar mi pintura. Habitualmente me meto en el tema elegido con pasión y curiosidad tales que sólo hay tiempo para documentarme y para sentir, y así poder expresar y transmitir, los símbolos y colores que son propios y a veces únicos, de cada asunto concreto. Es así que he querido elegir estas dos voces tan prestigiosas y sensibles con las que me he sentido en total comunión.

La primera, Carmen Rocamora, habla de mi evolución y con los años he podido ver que si la hubo en ese momento y muy clara además. La pintura se hace más densa, tanto en el color como en la observación de la realidad social circundante. La mujer en Africa, es la columna vertebral de la sociedad: trabaja en el campo, en la casa, en la oficina, y además tiene muchos hijos. Nunca pierde la sonrisa. Mi admiración por la mujer está patente en esta exposición: sólo hay mujeres y naturaleza.

Manuela Mena, entonces Subdirectora del Museo del Prado, habla también de esa evolución, pero apunta algo que para la mayoría quedaba oculto: en efecto, detrás de esos brillantes y luminosos colores, hay melancolía y sobre todo el aviso de un «mundo difícil» y amenazador. De hecho, en ese período, es cuando empiezo a utilizar la pintura como catarsis: la fuerte paleta cromática me servirá como ancla de salvación, es lo que me une con fuerza a la vida, y a la esperanza de tiempos mejores. La composición previene sobre un mundo duro, donde el peligro surge en un instante. Los colores no significan alegría, sino un desesperado deseo de vida.

Describe algo también presente en mi obra: el deseo de la veracidad, «el análisis riguroso del botánico», la voluntad de hacer descripciones que sean una crónica veraz bien sea etnológica, botánica o histórica, de acuerdo con cada una de las épocas.

\section{La crónica}

Decido releer «El diario de abordo» de Cristobal Colón, y por primera vez, un párrafo de ese diario me conmueve de manera definitiva:» Allende 


\section{Recuerdo, crónica, pasión y catarsis}

de escribir cada noche lo que el dia pasare, y el día lo que la noche navegare, tengo propósito de hacer carta nueva de navegar, en la cual situaré toda la mar y tierras del mar oceano en sus propios lugares, debajo de su viento, y más, componer un libro y poner todo por el semejante por pintura» (7).

Siguiendo el mandato del Almirante me puse a trabajar. A estudiar, primero, como fue la odisea de Colón, para conseguir la realización de su proyecto, como eran las cortes de España y Portugal en ese tiempo, sus personajes, y la cartografía. Y como era ese continente sorprendente que Colón descubrió maravillado.

Luego empecé a pintar, y me di cuenta, que los colores cambiaban, se hacían más luminosos, los horizontes eran más abiertos y amplios; la epopeya tenía que ser contada de una manera dinámica y esperanzada. Dinámica, porque así debían de ser esas gentes de España, que acababan de terminar una guerra de siglos, y que tendrían que canalizar esa energía en una empresa, que pudiera ilusionar a todo un país. Esperanzada, porque la ciencia, la cartografía, prometían un mundo amplio, casi ilimitado.

El resultado fue una exposición «Los viajes de Colón» que relataba los cuatro viajes del navegante. Por medio de 15 óleos grandes, 5 estudios preparatorios (al óleo también) y 14 acuarelas que eran estudios detallados para los cuadros posteriores. La exposición inauguró el Foro Iberoamericano de La Rábida el 24 de marzo de 1992, honrada con la presencia de S.M. la Reina. Me esperaba otra gran satisfacción: la segunda vez que se expuso «Los viajes de Colón» fue en mayo del mismo año en «La casa de la Entrevista», lugar donde los Reyes Católicos recibieron a Colón por primera vez, en 20 de enero de 1486. «Descenso a tierra: 12 de octubre de 1492»: «En octubre en San Salvador está terminando la estación de lluvias, los insectos son intolerables. Para alejarlos, los negros de hoy, como los indios de ayer, encienden hogueras para ahuyentarlos». Esta es la explicación de la luz que creyó ver Colón antes de que Rodrigo de Triana viera tierra.(8)

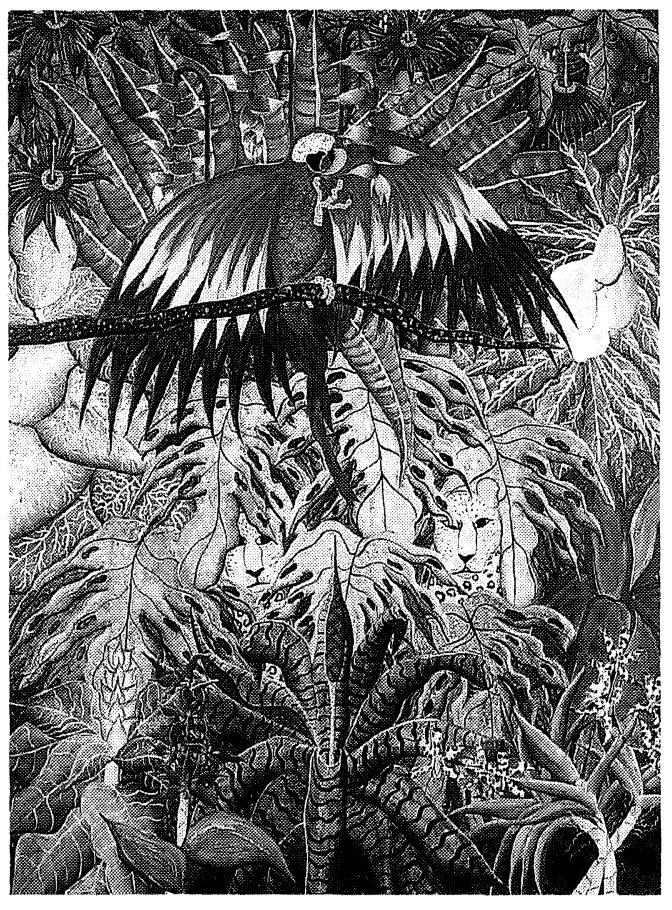

«Los viajes de Colón: flora y fauna. 
«IV Viaje: descubrimiento de Honduras, Costa Rica y Panamá, 1502». Colón zarpa de Cádiz el 9 de mayo de 1502 con 4 carabelas y a finales de julio, el almirante entra en contacto con los mayas. Será la primera vez que un hombre del viejo mundo, tiene noticia de esa cultura.

El cuadro tiene una atmósfera opresiva; el Almirante está enfermo; tiene gota y sufre una dolencia oftálmica que empezó en el tercer viaje; ha sufrido 26 tempestades y algún huracán, fenómeno que con el nombre caribe del dios del viento azota la zona de junio a septiembre. Tuvo también el Almirante, como relata en su carta a los Reyes, la experiencia de un eclipse, que aprovechó en su beneficio amenazando con él a los nativos si se negaban a denegar bastimentos que mucho necesitaba (9). Nos cuenta el almirante: «Parece que estas tierras están con Veragua, como Tortosa con Fuenterrabía, o Pisa con Venecia ... y no pudo haber yerro porque hubo eclipses, el sol estaba en Libra y la luna en Ariete» (10)

Presente en la escena, a su lado, por vez primera, un consuelo, su hijo Hernando con sólo 13 años, que con el tiempo se convertirá en el gran defensor de su padre, y realizará junto a Fray Bartolomé de las Casas la transcripción de «El diario de abordo».

\section{Catarsis}

«Flora y Fauna I-II-III»: estos cuadros de gran formato, representan el intercambio botánico que se produjo entre los tres continentes y es un estudio de diversas especies de flora y fauna.

Pero con la creación de esos tres cuadros, (que juntos son un panel de 4, $82 \times 2,10$ de alto) empieza mi etapa de utilización de la pintura como catarsis. Los colores son fuertes, agresivos, parecen muy alegres pero en realidad son un anhelo desesperado de vida. Es la creación, en una etapa dura, diría trágica, donde la composición se hace densa con posibles peligros en cada recodo del camino. Es un mundo hostil, que hay que vencer con gana de vivir, pensando en los que aún están... y quieren vivir.

En aquellos años, la pintura fue para mí, mi terapia. Mi tabla de salvación.

\section{La crónica}

La exposición «Los viajes de Colón», como decía, había sido para mí una necesidad de hacer la crónica de aquellos viajes extraordinarios y míticos, y una magnífica terapia en el momento oportuno. 
Unos meses más tarde, en septiembre, tuve «una oferta que no podía rechazar». Mi buena amiga María Rosa Calvo Manzano me entregó un manuscrito «El arpa en España, América y Filipinas», y me dijo que lo leyera y le dijera, si estimulaban mi imaginación. Siendo a propósito de América y España, pensaba María Rosa que me gustaría.

Lo leí de un tirón y me encontré con un mundo extraordinario: la organización sin fallo de las reducciones jesuiticas del Alto Paraná, con sus artesanos fabricando los instrumentos musicales, algunos desconocidos para ellos entonces, ya que europeos, como el arpa, que llegaría a ser el instrumento nacional de Paraguay, y no sólo componiendo música sino creando una red de distribución de dichos instrumentos musicales en gran parte de América.

En general, los misioneros de todas las órdenes religiosas, utilizaron la música, y también el teatro, como imán para atraer los indios a la religión, ya que éstos, en casi todas sus culturas, (inca, maya, azteca) utilizaban la música en sus ceremonias religiosas. Unido esto a la extraordinaria facilidad de estos pueblos para la música, ésta supuso un arma

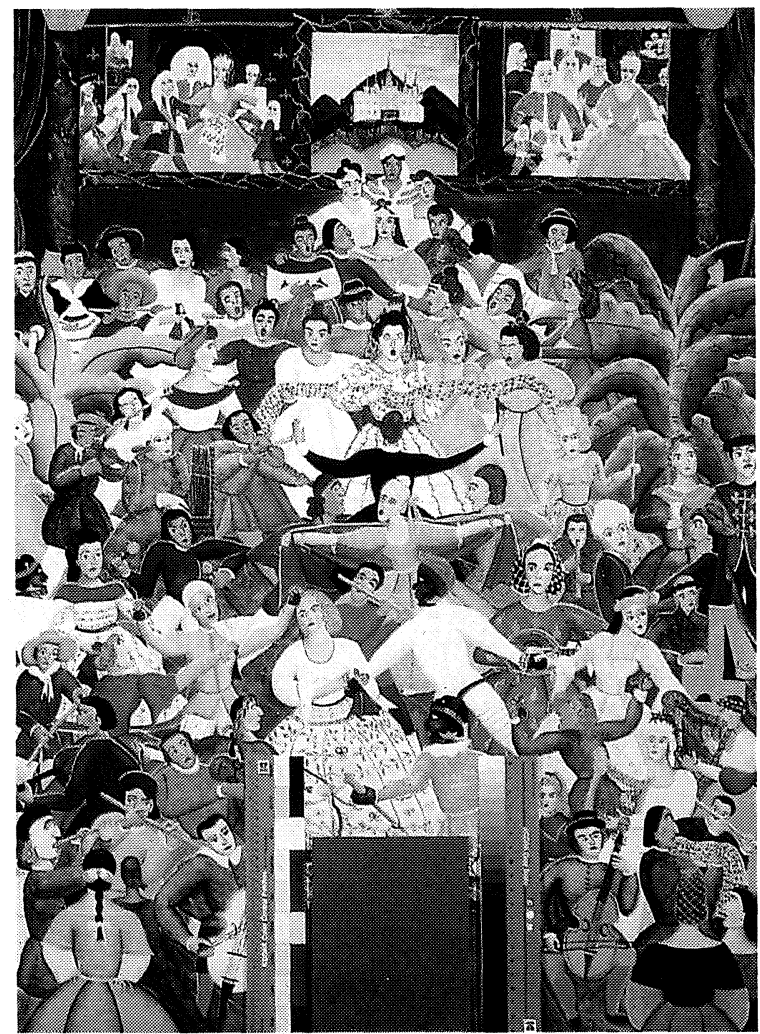

"Salón de música en Buenos Aires». formidable y bien empleada, para la evangelización.

El cuadro «Salón de música en Buenos Aires» nos relata la representación de la opera «La púrpura de la rosa» de Calderón de la Barca, con música de Tomás Torrejón. Dicha opera se estrena en Lima en 1701, en ocasión del advenimiento al trono de España de Felipe V, pero he querido situarla en Buenos Aires, porque en el siglo XVIII se crearon salones de música donde se representaban operas, y todo tipo de música culta y popular, incluso danzas extraordinarias. Destacan en esta época el violinista indio José Antonio Ortiz y el maestro de danza negro, Agustín Mejía (11).

Cada cuadro iba acompañado por unos versos de 
poetas españoles, San Juan de la Cruz, Rosalía de Castro, Garía Lorca, Gerardo Diego, y otros americanos como Sor Juana Inés de la Cruz, Amado Nervo, Dulce María Loynaz.

Me gustaría destacar entre la extraordinaria obra de Juana de Asbaje, Sor Juana Inés de la Cruz, unos versos sutiles y lucidos: «En perseguirme, mundo, que interesas? ¿En que te ofendo, cuando sólo intento poner bellezas en mi entendimiento, y no mi entendimiento en las bellezas?»

Esta exposición se presentó en la Casa de América el 23 de noviembre y tuvimos el honor de que S.M. la Reina Doña Sofía inaugurase la exposición, presidiendo la presentación del libro y el concierto de música barroca americana. El patrocinio de dicho acto corrió a cargo de la ONCE, que nos regaló una experiencia maravillosa de eficacia, y saber hacer.

La idea de «Hacedores de Europa» surgió a raiz de un viaje a Florencia, en 1992, con ocasión del V Centenario de Lorenzo De Medici. La lectura o relectura de Carlos I de Karl Brandi, o el «Lorenzo il Magnifico»

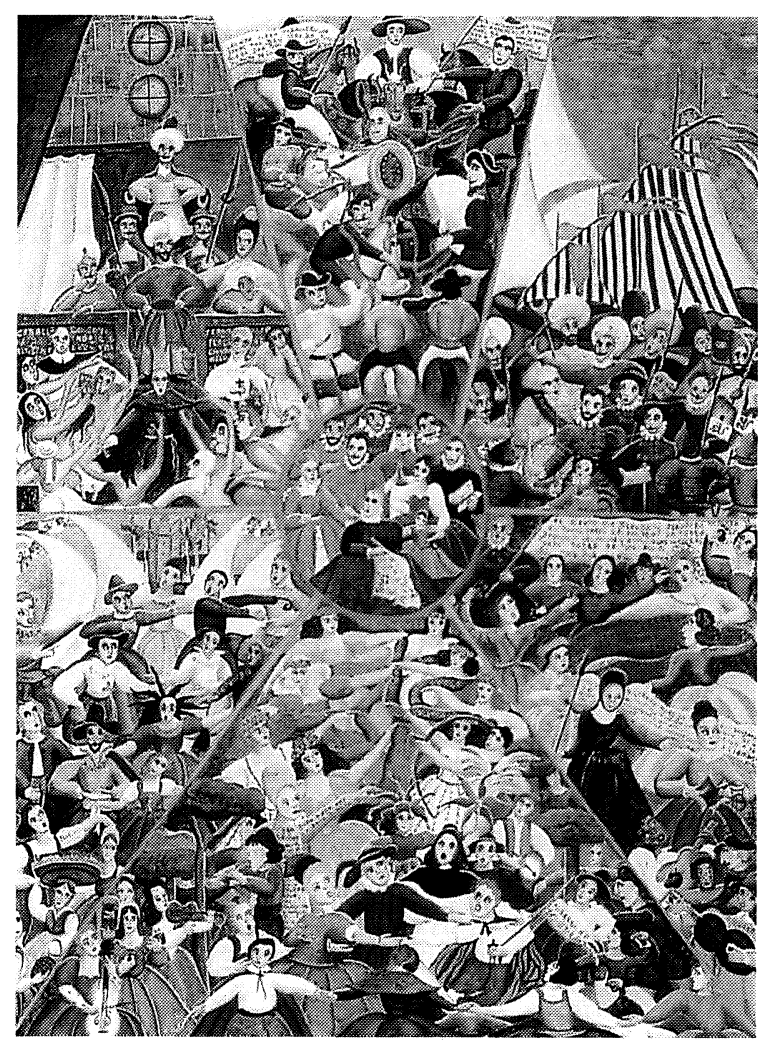

«Hacedores de Europa: Cervantes». de Ivan Cloulas, afirmaron la primera intuición. Pensé entonces que, por encima de guerras, fronteras y avatares de la historia, la cultura europea está siempre viva, construida paso a paso con aportaciones geniales de hombres extraordinarios que, en distintos campos, hicieron de Europa una cultura, no sólo para el viejo continente, sino para el mundo.

La composición se torna más estructurada, los personajes se multiplican y la paleta cromática debe representar su propia época. Empieza una período de mi pintura, caracterizada por la crónica y la documentación.

He dicho que los personajes se multiplican, y esto se debe a mi decisión de "po- 
ner en pintura» a todos aquellos personajes que contribuyen a crear una figura excepcional, aquellos que le preceden, preparando el camino, aquellos que le acompañan en su obra y aquellos que completan, más tarde, la misión comenzada.

Es la descripción del trabajo de equipo, la fuerza extraordinaria que adquiere un proyecto cuando se unen la voluntad y la mente de varias personas extraordinarias.

La exposición se inauguró el 23 de noviembre de 1995, en la Galería Kreyssler de Madrid.

Al comenzar a dar forma al proyecto, pensé que no podía quedarse en una exposición plástica, que había que hacerle hablar, ponerle la palabra, convertirla en un libro. E inmediatamente pensé en solicitar la ayuda y colaboración de personalidades ilustres que escribieron los textos de «Hacedores de Europa».

La documentación realizada para el cuadro de Aristóteles me aportó una serie de datos muy curiosos. Aristóteles en su tratado del color habla del azul noche «kuanós», del ocre, el blanco, el negro, un verde pálido, y sólo los colores que describe Aristóteles son con los que pinté ese cuadro.

El libro terminaba con «Mozart». Los colores son mucho más suaves, en la media tonalidad, azules-grisáceos, blancos-grisáceos, representan su época, y la composición es mucho más dinámica, intentando intensificarse con la intensa vida del personaje, sus luces y sus sombras.

Para Göethe el color es la trama esencial en el drama de la luz y las sombras. La teoría tiene una enorme importancia, porque sugiere explicaciones psicológicas de una gran profundidad.

La exposición se completaba con una serie de óleos y sus correspondientes estudios en acuarela, (una veintena de obras) que describían las plantas medicinales europeas.

Quisiera traer aquí y ahora, unos extractos de dos textos que significaron un gran regalo para mi. Regalo digo porque la

sensibilidad e inteligencia de Fernando Hurtado de Mendoza y el genio y magia de Pablo Antonio Cuadra, supieron ver ya algo que sólo esbozaba mi mente. A raíz de la presentación de «Hacedores de Europa» escribía Fernando: Todos los óleos, mandalas inconclusas, resultan concéntricos, lo que pudiere hacer pensar en el sol, y por ello, en colores calientes. No es así. Sus colores armonizando con las pequeñas figuras, resultan tenues y delicados. En la mayoría de los cuadros hay un mundo de agua y de luz, dentro de la plenitud de una atmósfera que se baña en un halo azulado.

Y si tuviéramos que abreviar la pintura de Pilar en una sola palabra, esta sería: Vida!.» (12) Me emocionó el artículo de Fernando, porque des- 
cubrió un motor de mi vida: el agua, el agua vida, el agua origen, el agua paz.

Decía así Pablo Antonio Cuadra: «Cierro el extraordinario libro, pero mi entusiasmo y admiración prosiguen. Pilar de Aristegui ha editado una carabela cultural -rebosante de pasajes de todos los tiempos, que ella pintó en una secreta sintaxis de fisonomías y colores y esa carabela viene de Europa, pero atraca y hace su puerto en todo corazón americano- y desembarca. Y nos estremece porque lo que nos trae, fresco y presionante, es nuestro destino, continuar, expandir sin solución de continuidad ese espacio cultural que llamamos Europa». (14)

Ambos habían intuido que el trabajo hecho, sobre Europa, era sólo una parte de un todo. La otra tenía que ser, debía de ser «Hacedores de América». Ellos sabían, yo sabía.

Había sido un proyecto hecho con esfuerzo e ilusión.

Ahora necesitaba hacer algo que, hundiendo los recuerdos en las raíces del pasado, fuera de nuevo una fiesta, algo lúdico y espontáneo.

Y así surgió «Cuatro propuestas para una exposición» que tendría lugar en la Galería Peironcely, en febrero de 1998.

Vivía yo en Roma, desde hacía un año, y los suaves terracotas, y los tenues verdes de ciudad tan hermosa, se iban adueñando de mis telas.

Los óleos, esta vez, serían escenas de ópera. Escenas que habían quedado fijadas en mi memoria a través de los años y los países.

Recuerdos vivos no aún nostalgia, de felicidad, que debe quedar fijada en la memoria, para cuando todo va mal, y parece que nunca escampará -nos sostenga su fuerza y su presencia.

La continuación lógica y cronológica de «Hacedores de Europa», debía ser, tenía que ser "Hacedores de América». La casi mítica historia de España en América, me había siempre fascinado. Las historias oídas en familia, recuerdos de los destinos en América de mis padres, se unieron pasando los años a mis propias vivencias, ya con mi marido y con mis hijos en Perú y Brasil, y los múltiples viajes que realizamos para tratar de conocer mejor esa América que nos cautiva y emociona de manera singular.

Este amor a un Continente espléndido, lleno de magia, de descubrimientos increíbles, de incógnitas históricas y de encuentro entre pueblos, me llevó a pintar los cuadros de "Hacedores de América».

En esta exposición presentada en La Casa de la Parra de la mítica ciudad de Santiago de Compostela, y en Madrid, en el Círculo de Bellas Artes, he querido transmitir mi admiración ante el prodigio de unas culturas, que naciendo por separado, supieron en encuentro fraterno, crear una cultura mestiza, llena de fuerza y dinamismo. 


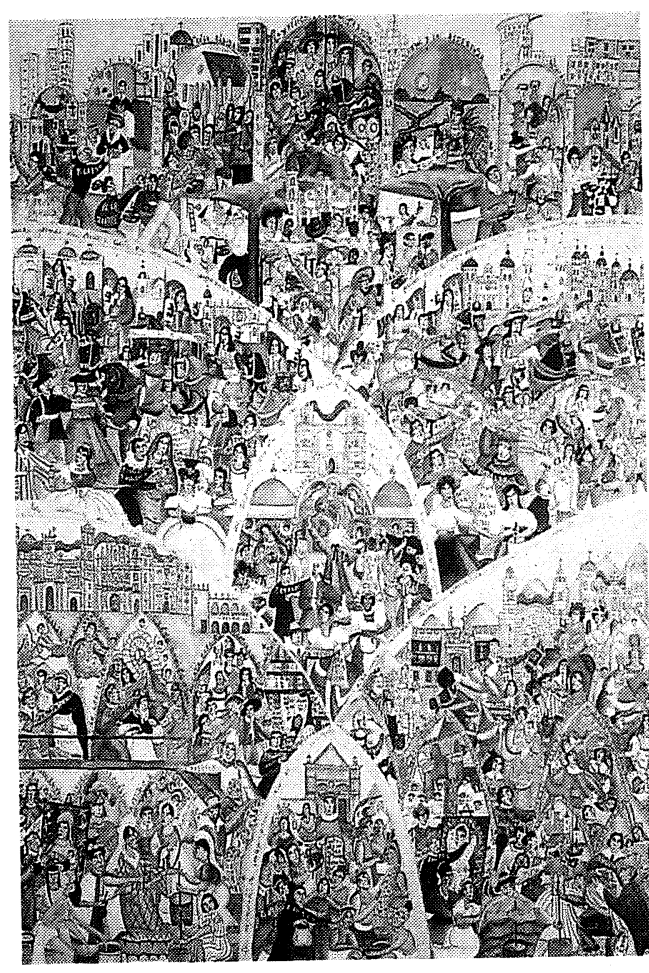

«Hacedores de América: la pintura y arquitectura».

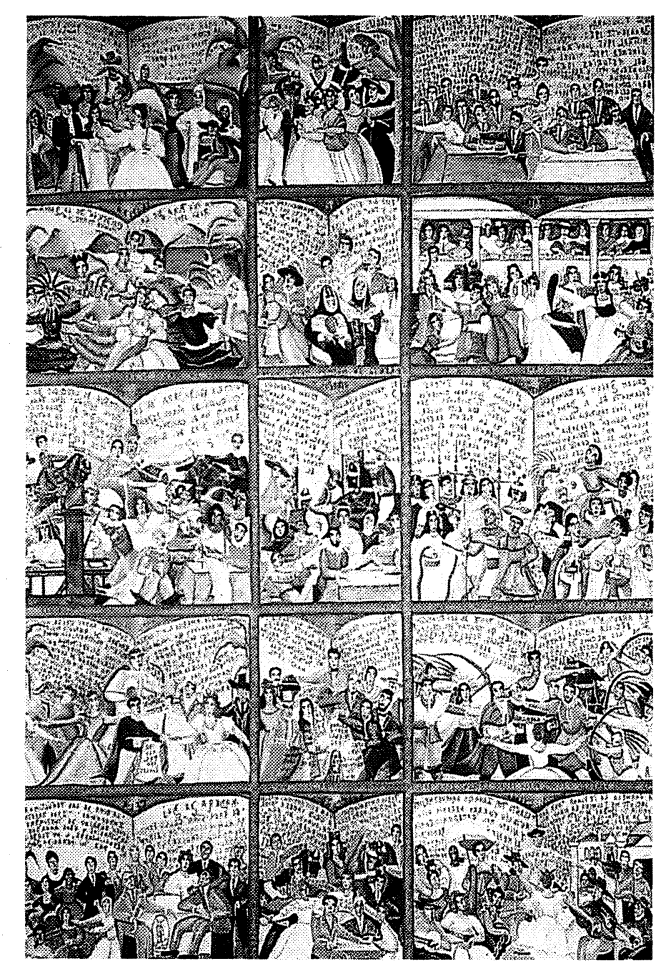

«Hacedores de América: la literatura».

Me gustaría poder transmitir el entusiasmo que yo siento por nuestra cultura común, y contagiar a los jóvenes el inmenso interés que se esconde, que vive, en las pirámides mayas y su literatura jeroglifica; la avanzada cultura de los Incas; la grandeza organizativa de los Aztecas; la inmensidad de las Pampas o la dulzura de las Islas, que influyó en un pueblo que se volcó en América con verdadera pasión, y produciría inigualables frutos, a través del mestizaje enriquecedor, en su barroco arquitectónico y pictórico; en el esplendor de su literatura; en su eficiente y solidaria evangelización; en sus intrépidas exploraciones; en sus magníficas Universidades; en sus nobles libertadores, y con la colaboración decisiva de sus «Hacedores Anónimos: la emigración».

En esta época ya se unen casi indisolublemente la crónica y la pasión.

Quiero hacer la crónica de una historia y de una cultura común, que, además de ser una interesantísima realidad, encierra un tesoro de información para comprender mejor América, y en consecuencia, a nosotros mismos.

Hay varios aspectos que quiero señalar en esta serie «Hacedores de América»: uno es la participación activa y fundamental de la mujer, en la construcción de América. 
$\mathrm{El}$ otro aspecto que me parece destacable, es la participación de vascos, con la Corona de Castilla, sobre todo, en la navegación y las exploraciones.

La Comisaria de la exposición en Santiago de Compostela, tuvo la idea excelente de comenzar la exposición con unos cuantos cuadros de «Los viajes de Colón» ya que con este trabajo, empezaba la serie de exposiciones de contenido netamente histórico.

Siendo «Hacedores de Europa» la segunda exposición histórica, seleccionamos «Guttenberg o la imprenta», «Don Enrique el Navegante», «Lorenzo de Medici», «Descartés o la razón» $\mathrm{y}$ «Van Leeuwenhoeck el inventor del microscopio».

El núcleo de la exposición es «Hacedores de América» que quiere presentar grandes personajes que en distintas actividades, en ambos lados del Atlántico, contribuyeron de forma decisiva a forjar América».

El primer cuadro «las culturas pre-colombinas» comienza con una leyenda, sacada del Libro Sagrado de los Mayas, descubierto en 1705, por el Fraile español Ximénez. Al fondo, las ruinas de Copan descubiertas en el siglo XVIII por Diego Palacios.

A la izquierda, tenemos la representación de las culturas Tairona y Kimbaya de Colombia; los Cañaris de Ecuador, los Guaranies del Alto Paraná; y los Indios pueblo, Zuñis y Yaquis de Nuevo Méjico y Arizona. A la derecha, las culturas de la Costa del Perú: Nazka, Chimú, Chavin, Mochica, Paracas y Lambayaque.

Encima, los Incas organizadores y guerreros, con Pachacuti coronado Rey en 1438 después de tomar la ciudad de Cuzco. Los colores son los propios de estas culturas: rojos tierra, blancos, ocres y negros. También están presentes los Olmecas, con sus característicos y extraordinarios tocados. Y por últimos los Aztecas, o Mexica Tenochticlan que del $1111 \mathrm{al}$ 1521 D.C. dominaron los pueblos vecinos. La escena está presidida por Quetzalcoalt, la serpiente emplumada, Tlaloc, dios de la lluvia y Huitziloochtili, dios de la guerra. Presente también Fray Bernardino de Sahagun gran narrador del mundo azteca, en el siglo XVI.

\section{La navegación}

La famosa frase de Nicolás Nicolai, astrónomo de Catalina de Medicis: «Oh feliz nación española, cuán digna eres de loor en este mundo, que ningún peligro de muerte ....» (15) divide el cuadro, en forma de rosa de los vientos en cuyos rayos está escrito dicho poema, de alabanza al valor de España, y las penalidades que tuvieron que pasar los españoles en algunos de esos viajes. 


\section{Recuerdo, crónica, pasión y catarsis}

\section{La literatura}

En el centro Cervantes, con alguno de sus personajes, y textos de «El Quijote» y de «El celoso extremeño».

Los otros espacios nos cuentan: la literatura precolombina; la crónica; el teatro; la poesía; la opera; la epopeya; la narrativa; el periodismo; Rubén Darío; los premios Nobel.

El siguiente apartado contempla la obra de Valle Inclán. Sigue el realismo mágico; García Lorca.

Sigue América 2000 donde están presentes escritores americanos. Termina el cuadro, Camilo José Cela.

Completan el libro: «La pintura y la arquitectura»; «El gobierno»; «La evangelización»; «El mestizaje»; «Los

libertadores»; «La universidad» y «La emigración: hacedores anónimos».

En resumen y como veis, la pintura para mi ha sido y es eso. Un oficio de sentidos y también de alma. He pintado y pinto con los cinco sentidos. Veo y percibo magníficos colores. Oigo y traduzco los sonidos en matices. Huelo y concreto los olores en gamas y luces. Toco y convierto los objetos en texturas. Paladeo los frutos y esencias y los asimilo en colores y geometrías.

Por eso la pintura para mi es parte importante e integrante de mi persona, la forma plástica de sentir y expresarme, de recordar y decir, de contar y explicarme. Es recuerdo, crónica, pasión y catarsis y siempre doy gracias al Señor y a la cultura de mi país que me ha regalado este gran bien que es tan grato compartir.

\section{Notas}

1 Pág.5. Sara Facio-María Cristina Orive, Miguel Angel Asturias. "Actos de fe en Guatemala» La Azotea. Buenos Aires 1980.

2 Bishop, ROBERT. (1986). Introducción al catálogo «Guatemala is a festival» Meridien House International, Washington D.C.

3 Petterssen, Clara. "Maya de Guatemala» Museo Ixchel de Textiles. Guatemala, 1984.

4 Smothers, Mary AnN. «Rosita's Christmas Wish" San Antonio Light 1981.

5 Rocamora, CARmen. «Pilar de Arístegui, La Naturaleza desde la vera onírica», «El punto de las artes", Madrid, Diciembre 1991.

6 Mena, Manuela. Subdirectora del Museo del Prado, Introducción al catálogo «Kenia, la bella», Madrid, Diciembre 1991.

7 Colón, CRistóbal. «Diario de abordo» Ed. Eurohelver Madrid, 1991.

8 Taviani, Paolo Emilio. «Los viajes de Colón» Ed. Planeta-Agostini, Novara, 1984. 
9 MAdARIAGA, SALVADOR DE. «Vida del muy magnífico señor don Cristóbal Colón» Ed. Espasa-Calpe Madrid 1975.

10 COLÓN, CRISTÓBAL. "Carta del almirante a los Reyes de España".

11 CALVo Manzano. «El arpa en España, América y Filipinas» Ed. Simancas Madrid 1993.

12 Hurtado de Mendoza, Fernando. «Diario de las Américas», Miami 1996.

14 Cuadra, Pablo Antonio. «Hacedores de Europa: un libro estraordinario", «La prensa literaria" Managua 21 diciembre 1996.

15 GONZÁLEZ ALLER, JOSÉ IGNACIO. «Hacedores de América: La navegación» Ed. Lunwerg; Madrid 2000.

\section{Bibliografía}

Bernales Ballesteros, JoRge. «Historia del arte hispanoamericano», Alhambra, Madrid 1988.

BisHOP, RoBERT. «Guatemala es a festival» (catálogo) Meridien House Int. Washington, 1986.

Facio, Sara; Orive, María Cristina; Asturias, Miguel Ángel. «Actos de fe en Guatemala", la Azotea, Buenos Aires, 1980.

MADARIAGA, SALVADOR. "Vida del muy magnífico señor don Cristobal Colón», Ed. EspasaCalpe, Madrid 1975.

GonZÁlEZ-AlleR, JosÉ IgNACIO. «Hacedores de América: la Navegación».Ed.Lunwerg, Madrid 2000.

Mena, Manuela. «Kenia, la bella» (catálogo) diciembre 1991.

Petterssen, Clara. «Maya de Guatemala» Museo Ixchel de Textiles, Guatemala 1984.

Perry, Frances; Greenwood, Leslie. «Flowers of the world» Ed. Hamlyn, Londres 1972.

QUINTO CENTENARIO. «Crónica de América», Plaza y Janés, Esplugues de Llobregat, 1990.

ROCAMORA, CARMEN. «El punto de las artes», Madrid, diciembre 1991.

SMOthers, MARY ANN. «Rosita's christmas wish», San Antonio Light 1981.

Zalamea, Alberto. «Pensamiento, poesía y arte de Iberoamérica siglo XX”. Nomos impresores. Bogotá, 1993. 